\title{
Sodium nanofluid for efficient oil recovery in heavy oil and oil sand reservoirs
}

\author{
Danial Zareei ${ }^{1, \#,}$, Dan Luo ${ }^{2, \#}$, Konstantinos Kostarelos ${ }^{1}$, Zhifeng Ren $^{2}$ \\ 1Department of Petroleum Engineering, University of Houston, Houston, TX 77204, USA. \\ ${ }^{2}$ Department of Physics and Texas Center for Superconductivity at the University of Houston (TcSUH), University of Houston, \\ Houston, TX 77204, USA. \\ ${ }^{\#}$ Authors contributed equally.
}

Correspondence to: Prof. Konstantinos Kostarelos, Department of Petroleum Engineering, University of Houston, 5000 Gulf Freeway Bldg 9, Houston, TX 77204, USA. E-mail: kkostarelos@uh.edu; Prof. Zhifeng Ren, Department of Physics and Texas Center for Superconductivity at the University of Houston (TcSUH), University of Houston, 3369 Cullen Blvd, Houston, TX 77204, USA. E-mail: zren@uh.edu

How to cite this article: Zareei D, Luo D, Kostarelos K, Ren Z. Sodium nanofluid for efficient oil recovery in heavy oil and oil sand reservoirs. Soft Sci 2021;1:8. https://dx.doi.org/10.20517/ss.2021.08

Received: 29 Jul 2021 First Decision: 2 Sep 2021 Revised: 7 Sep 2021 Accepted: 8 Sep 2021 First online: 8 Sep 2021

Academic Editor: Cunjiang Yu Copy Editor: Xi-Jun Chen Production Editor: Xi-Jun Chen

\begin{abstract}
Nanomaterials exhibit unique chemical and physical properties in comparison with their bulk-phase counterparts, attracting significant attention from the oil and gas industry in the hope of solving challenging issues. Current heavy oil extraction methods are costly and have unsatisfactory efficiency, and facing environmental restrictions increasingly. Our recent introduction of sodium $(\mathrm{Na})$ nanofluid provides a promising method for heavy oil extraction since it shows improved oil recovery without burning carbon-containing fuels. Here, we conducted coreflooding tests to further evaluate the effect of this Na nanofluid on recovering oil from different formations, which had not been previously demonstrated, as well as to deepen our understanding of the underlying mechanisms. The $\mathrm{Na}$ nanofluid exhibited excellent oil-extraction efficiency for both types of heavy oil tested. The recovery mechanisms were found to be complicated. We also found that post-injection soaking and using the proper solvent to disperse the sodium nanoparticles are important for further boosting oil recovery.
\end{abstract}

Keywords: Sodium nanoparticles, heavy oil, oil sands, enhanced oil recovery, bitumen 


\section{INTRODUCTION}

Oil with API gravity lower than $22.3^{\circ}$ is categorized as heavy oil and, if less than $10^{\circ}$, as extra-heavy oil ${ }^{[1]}$. Low API gravity is due to the presence of a large fraction of high-molecular-weight components in crude oil that leads to high viscosity, resulting in low mobility in porous rock $^{[1-4]}$. For highly viscous crude oil, viscosity reduction has become the main philosophy in developing methods to extract subsurface oil. Extremely viscous oil containing the largest fractions of high-molecular-weight hydrocarbons is denoted bitumen, in which the oil is a sticky and black semi-solid. Bitumen is often found in shallow formations in which, together with sand, clay, and water, it becomes oil sand ${ }^{[3]}$. Heavy oil recovery techniques developed during the past several decades fall into two categories based on the reservoir depth: surface mining used for shallow deposits at depths of less than $200 \mathrm{~m}$ and in situ recovery for deeper deposits. Surface mining typically uses the combination of hot water and a light-hydrocarbon solvent to separate bitumen from excavated oil sand $s^{[5,6]}$. On the other hand, in situ recovery from heavy oil reservoirs requires a much wider range of techniques due to the greater number of parameters controlling the process in comparison with surface mining. That is to say, the heterogeneity of porous rock structures, varied oil compositions and viscosities, variations in formation depths and wettability, and unpredictable fluid distribution all demand various non-thermal or thermal methods for in situ recovery ${ }^{[7,8]}$. Thermal methods dominate in practice for the relatively more viscous oil ( $>200 \mathrm{cP} ; 1 \mathrm{cP}=1 \mathrm{mPa} \cdot \mathrm{s}$ ) and layers at least $10 \mathrm{~m}$ thick are needed for cyclic steam injection, while steam-assisted gravity drainage requires layers at least $30 \mathrm{~m}$ thick to make extraction economical ${ }^{[4,9]}$. Injections of gases, surfactants, polymers, and light-hydrocarbon solvents are used for thinner layers and less viscous oil ${ }^{[10-13]}$. As climate change has become more prominent, the injection of carbon dioxide for enhancing heavy oil recovery is currently attracting increasing research attention ${ }^{[14-16]}$.

Given the increasingly severe restrictions on greenhouse-gas emissions, combusting fuels to produce steam for heavy oil recovery will continue to become more expensive, searching for environmentally friendly and economical alternative methods to extract heavy oil is urgent. In recent years, significant attention has been paid to nanomaterials since they exhibit unique chemical and physical properties not found in their corresponding bulk phases ${ }^{[17,18]}$. Thus far, nanomaterials have been applied to play several roles in heavy oil recovery, including adsorption of asphaltene ${ }^{[1,20]}$, modification of fluid rheology ${ }^{[2-23]}$, catalysis in the aquathermolysis process ${ }^{[24-26]}$, generation of Pickering emulsions ${ }^{[27-30]}$, etc. Many issues still need to be resolved in order to use nanomaterials for practical field applications, including inexpensive large-scale material synthesis and high recovery performance. Luo and $\operatorname{Ren}^{[31]}$ recently reported a novel type of reactive sodium $(\mathrm{Na})$ nanoparticles for in situ extra-heavy oil extraction. These particles utilize the reaction between sodium and water, producing many benefits for displacing underground oil, namely heat, an alkaline environment, and hydrogen gas. In addition, sodium nanoparticles can be manufactured simply and economically. While this work is promising, more research is needed to determine the effect of sodium nanofluid on recovering oil with different viscosities and in different formations. For example, a range of crude oil types needs to be explored, and the dispersant used for the nanofluid along with its role in the injection process need to be better understood. Additionally, the methodology for deployment needs to be evaluated, including determining whether a single application is adequate and if soaking time is required.

We investigated the use of sodium nanoparticles for two applications that differ significantly: recovery of (1) heavy oil with a viscosity of approximately $2000 \mathrm{cP}$ from a synthetic sandstone core under confining stress and (2) semi-solid bitumen from oil sands not subjected to confining stress. Each application incorporated a series of batch tests and flow experiments. The experiments for these two applications resulted in incremental oil recovery values of $38.5 \mathrm{wt} . \%$ (heavy oil) and $33.6 \mathrm{wt} . \%$ (oil sand), demonstrating the capability of sodium nanofluid in two widely differing reservoir conditions. Based on the results of this research, we conclude that sodium nanofluid has a high potential to enhance the recovery of heavy and 
extra-heavy crude oil for a range of reservoir conditions.

\section{MATERIALS AND METHODS}

\section{Synthesis of sodium nanofluid}

The detailed synthesis procedure was reported previously ${ }^{[31]}$. Briefly, $5 \mathrm{~g}$ bulk sodium metal was mixed with $150 \mathrm{~mL}$ silicone oil (viscosity of 45-55 cP), and the mixture was sheared in a blender (Biolomix, model G5200). After shearing the mixture for $15 \mathrm{~min}$, the silicone-oil-dispersed sodium nanofluid shown in Figure 1A was used in synthetic sandstone flooding experiments for heavy oil recovery. The silicone oil can be further removed from sodium nanofluid via centrifugation. The chemical and colloidal stability of this nanofluid was previously demonstrated ${ }^{[31]}$ and was also confirmed here by the absence of any observable precipitates over the course of one week. For the oil-sand experiments using pentane-based nanofluid, the silicone-based sodium nanofluid was prepared and then centrifuged at $4000 \mathrm{rpm}$ for $30 \mathrm{~min}$ to remove the silicone oil. Pentane was then added to re-disperse the sodium nanoparticles at $33 \mathrm{mg} / \mathrm{mL}$. All of the chemicals mentioned here were purchased from Sigma-Aldrich.

\section{Heavy oil recovery}

Batch tests

Preliminary batch tests were conducted by mixing $1 \mathrm{~g}$ of heavy oil $\left(2000 \mathrm{cP}\right.$ at $25^{\circ} \mathrm{C}, 12.5^{\circ} \mathrm{API}$ gravity, confidential oilfield), $40 \mathrm{mg}$ sodium nanoparticles dispersed in $0.2 \mathrm{~mL}$ silicone oil, and $1 \mathrm{~mL}$ brine containing $5.66 \mathrm{wt} . \% \mathrm{NaCl}$ in a glass vial in order to confirm the generation of gas and heat due to sodium reacting with water ${ }^{[3,32]}$. Once the reaction was demonstrated, $9 \mathrm{~mL}$ of brine was further added to the vial and shaken by hand for a few seconds to determine whether sodium hydroxide reacts with any naphthenic acid in the oil to generate surfactants or "soap"

\section{Heavy oil core flood procedure}

Synthetic sandstone cores were fabricated to evaluate the performance of silicone-based sodium nanofluid for the recovery of $2000 \mathrm{cP}$ heavy oil. To ensure homogeneous fabrication, a series of steps developed by Kostarelos and Myers at the University of Houston were followed as shown in Figure 1B using OK-75 grade sand (99.8 wt.\% silicon dioxide SG $=2.65$, U.S. Silica) ${ }^{[34]}$. Particle size analysis by the sand supplier is displayed in Figure 1C, which shows that the majority of the sand is within 105-297 $\mu \mathrm{m}$. The fabrication results in homogeneous synthetic sandstone core $3.8 \mathrm{~cm}(1.5$-inch) in diameter and approximately $30 \mathrm{~cm}$ (12-inch) long that can be trimmed to the needed length.

Two core flooding tests were conducted using synthetic sandstone cores and the same heavy oil: a control experiment using silicone oil and another using silicone-oil-based nanofluid. Each synthetic sandstone core was trimmed to $12.7 \mathrm{~cm}$ in length for flow experiments using high-pressure core flooding equipment, as illustrated in Figure 2A. For each core flood, a core was loaded into the 10,000 psi-rated Hassler-type highpressure core holder (Phoenix Instruments) shown in Figure $2 \mathrm{~B}$ ( $1 \mathrm{MPa} \approx 145 \mathrm{psi}$ ), which is capable of accommodating 1.5-inch-diameter cores of up to 12 inches in length. The porosity and permeability of each core were measured using brine $(5.66 \mathrm{wt} . \% \mathrm{NaCl})$ under a confining pressure of $700 \mathrm{psi}$. A residual oil saturation was then established using a rate of $0.077 \mathrm{~mL} / \mathrm{min}(1 \mathrm{ft} /$ day $)$ while maintaining confining pressure of 700 psi.

The control experiment consisted of core flooding using only silicone oil (no Na nanoparticles) to quantify the oil recovery due to the dispersant alone. Silicone oil was injected at a rate of $0.03 \mathrm{~mL} / \mathrm{min}(0.4 \mathrm{ft} /$ day $)$ in a downward direction for a gravity-stable displacement. Examining the produced fluids provides a qualitative measure of the oil recovery, but a quantitative measurement was made based on the analysis of 
A
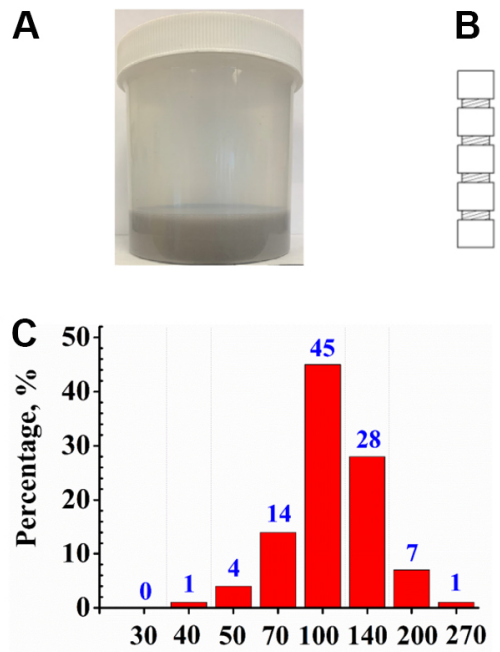

U.S. Sieve Mesh

B

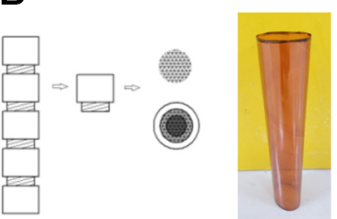

Sand pluviation

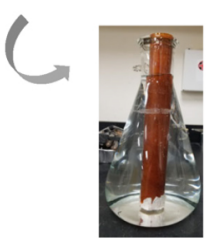

Water saturation Solidification using liquid $\mathrm{N}_{2}$

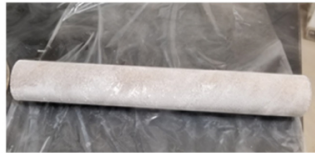

Synthetic core

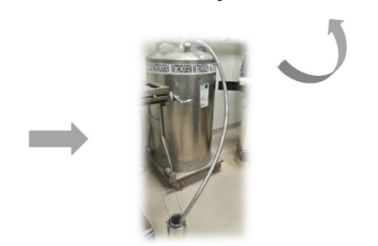

(a)

Figure 1. (A) Image of silicone-oil-dispersed sodium nanofluid. (B) Steps in fabricating a synthetic sandstone core. (C) Sand size distribution using the sieve mesh method.
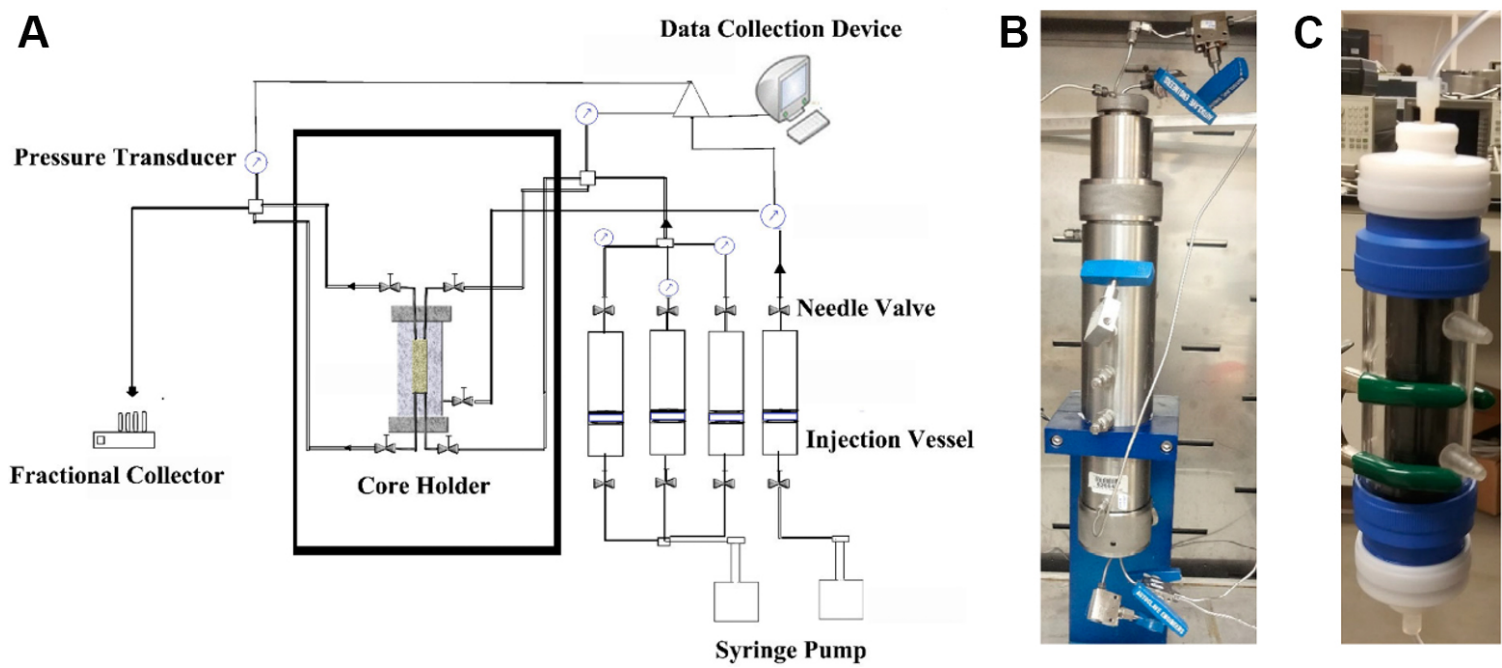

Figure 2. (A) Schematic illustration of the core flooding equipment. (B) High-pressure core holder for synthetic sandstone core flooding. (C) Glass column for oil sand pack flow experiments.

the remaining oil within the synthetic sandstone core. In detail, toluene was injected into the core to dissolve any remaining oil and was further analyzed using a gas chromatograph and mass spectrometer (Agilent GC/MS model 7890B/7693A) to quantify the concentration of dissolved heavy oil. The analytical approach relied on tracking targeted compounds in the heavy oil that were separated using an inlet temperature of $250{ }^{\circ} \mathrm{C}$ and an initial oven temperature of $50{ }^{\circ} \mathrm{C}$ for $1 \mathrm{~min}$, ramping up $5{ }^{\circ} \mathrm{C}$ per min to $300^{\circ} \mathrm{C}$, and maintaining this temperature for $40 \mathrm{~min}$. The column used was the Agilent 19091S-433UIHP5MS (Ultra Inert, $30 \mathrm{~m}$ length, $0.25 \mathrm{~mm}$ diameter, $0.25 \mu \mathrm{m}$ coating). The chromatograph was generated with a flame ionization detector, using an air and hydrogen mixture (further details are provided in reference ${ }^{[35]}$ ).

A second synthetic core was then prepared and characterized. Residual oil saturation was established for the core flooding test using sodium nanofluid, which was initiated using silicone-oil-dispersed sodium 
nanoparticles at $33 \mathrm{mg} / \mathrm{mL}$ concentration at a rate of $0.03 \mathrm{~mL} / \mathrm{min}(0.4 \mathrm{ft} /$ day $)$ in a downward direction for a gravity-stable displacement. A total of 0.65 pore volume (PV) of nanofluid was injected during the first cycle, followed by brine injection in the downward direction at the same rate, producing oil, and continued until oil production was no longer observed (4.0 PV of brine). A second cycle consisting of an additional $0.3 \mathrm{PV}$ of nanofluid was then injected, followed by $2.25 \mathrm{PV}$ of brine, after which an insignificant amount of oil was produced. The produced fluids were photographed, and the oil recovery was quantitatively measured based on analysis of the remaining oil within the synthetic sandstone core as described above.

\section{Oil sand (bitumen) recovery}

Batch tests

Oil sands were obtained from Alberta Innovates and were labeled "Athabasca oil sands high grade". The high-grade oil sand contains $12.7 \mathrm{wt}$ \% bitumen. As shown in Table 1, a Soxhlet extraction and SARA analysis of the bitumen were performed ${ }^{[35]}$.

Static experiments were conducted by mixing $8 \mathrm{~g}$ of the oil sand with brine, a combination of brine and silicone oil, or a combination of brine and silicone-oil-based nanofluid. The composition of each sample is shown in Table 2, with sample numbers corresponding to the photographs in Figure 3. The vials were examined for any color change of the liquid, indicating oil liberated from the solid to the liquid phase. The tests were conducted at both $22{ }^{\circ} \mathrm{C}$ and $50{ }^{\circ} \mathrm{C}$.

\section{Packed oil sand flow experiments}

Three flow experiments using packed oil sand columns were conducted using silicone-oil-based nanofluid, pentane-based nanofluid, or pentane alone as a control. The oil sand packs were prepared by packing in lifts of 1 inch $(2.5 \mathrm{~cm})$ and compacting the oil sand within a Kimble-Chase Kontes Chromaflex glass column $15.0 \mathrm{~cm}$ in length and $2.5 \mathrm{~cm}$ in diameter as shown in Figure $2 \mathrm{C}$. The porosity and permeability of each oil sand pack were measured following the same procedures as for the synthetic sandstone core flow tests, except that no confining pressure was applied. Thus, in these flow experiments, either nanofluid or pentane was employed after characterizing the pack. Nanofluid with a concentration of $33 \mathrm{mg} / \mathrm{mL}$ or pentane was injected (0.50 PV) in an upward flow direction at a rate of $10 \mathrm{~mL} / \mathrm{min}$ so that, in the case of the nanofluid tests, the nanoparticles could be distributed throughout the pack quickly before reactions could occur. To ensure that an adequate amount of water was available to react with the sodium nanoparticles, $0.50 \mathrm{PV}$ of brine was then injected (upward) and allowed to soak for $74 \mathrm{~h}$ to further promote the interactions between the nanoparticles and the brine, as well as between the oil and the alkali. This was followed by four cycles of brine injection (5 PV, $5 \mathrm{PV}, 1 \mathrm{PV}$, and $0.5 \mathrm{PV}$ ) at a lower rate of $0.085 \mathrm{~mL} / \mathrm{min}(3.0 \mathrm{ft} /$ day), each followed by a $24 \mathrm{~h}$ soak period. The recovery factor was calculated gravimetrically: each column was dried and weighed to determine the mass difference compared with the initial mass.

\section{RESULTS AND DISCUSSION}

\section{Heavy oil recovery}

Batch tests

Upon combining the heavy oil, silicone-based nanofluid, and brine, gas bubbles were observed immediately [Figure $4 \mathrm{~A}$ ], and the heat was generated as evidenced by handling the vial. In the proposed application, the hydrogen gas generated by the reaction could provide energy within the reservoir and swell the heavy oil to aid in displacement. Adding $9 \mathrm{~mL}$ more brine and shaking the vial by hand for a few seconds resulted in an emulsion, which dilution testing showed to be of the oil-in-water type. As shown in Figure $4 \mathrm{~B}$, the diameters of the oil droplets in the emulsion are about or less than $10 \mu \mathrm{m}$, demonstrating that a surfaceactive chemical was generated to stabilize the emulsion. These observations are evidence that sodium 
Table 1. SARA results for bitumen used in the current study ${ }^{[35]}$

\begin{tabular}{llll}
\hline Saturates (\%) & Aromatics (\%) & Resins (\%) & Asphaltenes (\%) \\
\hline 23.85 & 28.21 & 15.13 & 32.81 \\
\hline
\end{tabular}

Table 2. Composition of vials prepared for static experiments

\begin{tabular}{llllll}
\hline Sample No. & Oil sand mass $(\mathbf{g})$ & Nanofluid $(\mathbf{g})$ & Silicone oil $(\mathbf{g})$ & Brine $(\mathbf{g})$ & Temperature $\left({ }^{\circ} \mathbf{C}\right)$ \\
\hline a (left) & 8 & - & - & 12.6 & 22 \\
a (right) & 8 & - & - & 12.6 & 50 \\
b (left) & 8 & - & 2.6 & 10.5 & 22 \\
b (right) & 8 & - & 2.6 & 10.5 & 50 \\
c (left) & 8 & 2.6 & - & 10.5 & 22 \\
c (right) & 8 & 2.6 & - & 10.5 & 50 \\
\hline
\end{tabular}
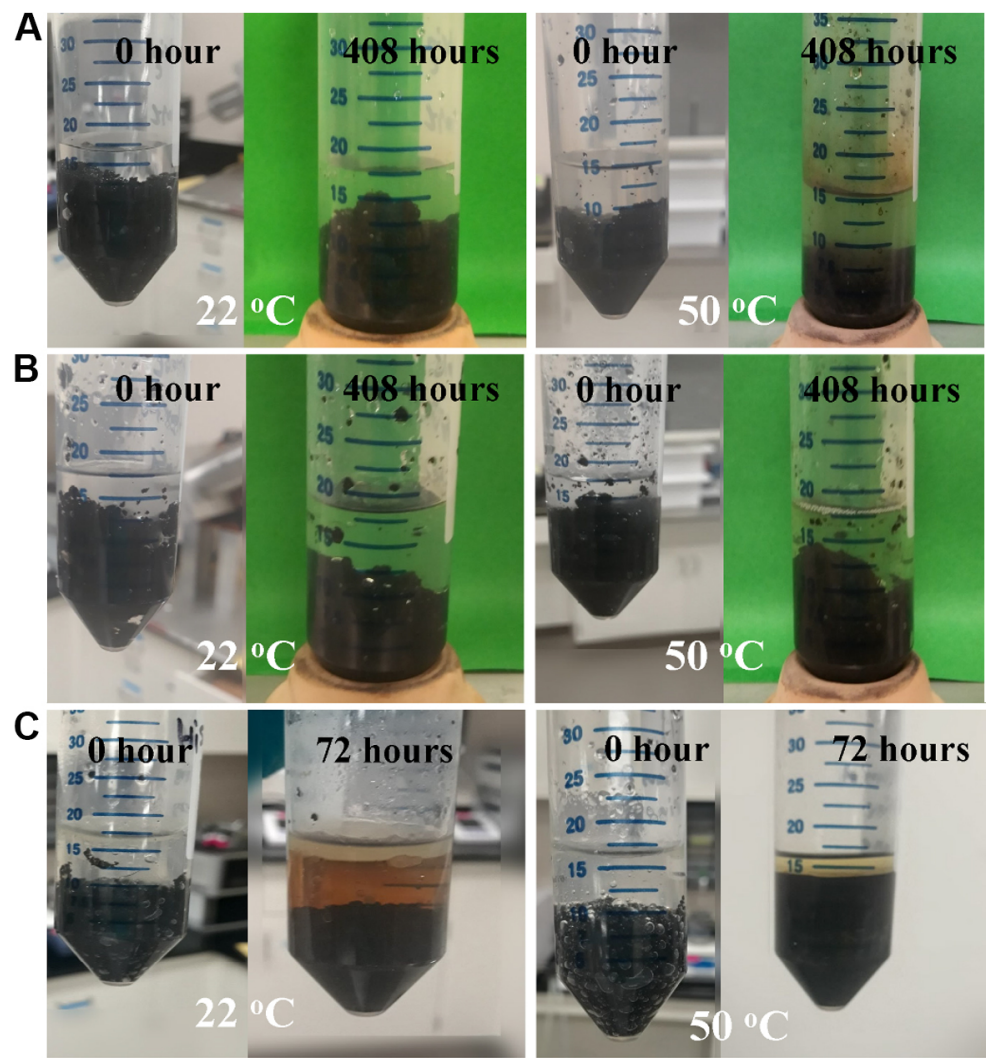

Figure 3. Results from six static experiments in which oil sands were mixed with (A) brine, (B) silicone oil and brine, or (C) sodium nanofluid and brine. Individual photographs show initial results and those after soaking for at least $72 \mathrm{~h}$ at $22^{\circ} \mathrm{C}$ and $50^{\circ} \mathrm{C}$.

hydroxide was produced and that it reacted with the naphthenic acid in the heavy oil in a saponification process $^{[33]}$.

\section{Heavy oil core flood}

Table 3 lists the porosity and permeability values of the synthetic sandstone cores used in the flooding tests, which reflect highly permeable and porous reservoir conditions. These conditions are typical of relatively shallow layers and are in highly viscous oil reservoirs. Core No. 1 was used to determine the oil recovery of 
Table 3. Properties of synthetic sandstone cores used in flooding tests

\begin{tabular}{lllll}
\hline Experiment No. & Length $(\mathbf{c m})$ & Diameter $(\mathbf{c m})$ & Porosity $(\%)$ & Permeability $(\mathbf{D})$ \\
\hline 1 (silicone oil) & 12.7 & 3.8 & 28.8 & 13.9 \\
2 (nanofluid) & 12.7 & 3.8 & 29.2 & 14.1 \\
\hline
\end{tabular}
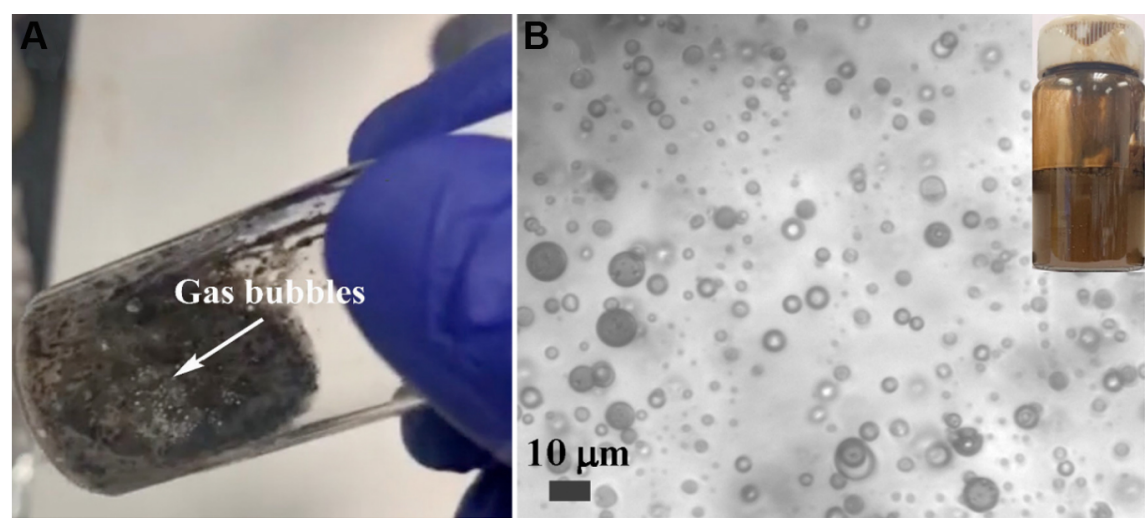

Figure 4. (A) Mixture of $1 \mathrm{~g}$ heavy oil, $40 \mathrm{mg}$ sodium nanoparticles dispersed in $0.2 \mathrm{~mL}$ silicone oil, and $1 \mathrm{~mL}$ brine containing $5.66 \mathrm{wt} . \%$ $\mathrm{NaCl}$. (B) Optical image of the emulsion formed by the heavy oil, sodium nanofluid, and brine. Inset: photograph of the emulsion sample.

the control experiment using only silicone oil, while core No. 2 was used to evaluate the sodium nanofluid. The control experiment No. 1 produced $6.5 \%$ of the original oil in place (OOIP), as shown in Table 4 . The mechanisms for oil recovery in the control experiment include the change in mobility ratio that improves the sweep efficiency.

Oil was produced during the first cycle of nanofluid and brine flooding in core flood experiment No. 2. The second cycle of nanofluid/brine flooding, however, did not result in significant additional oil recovery. The reason could be that the major flow resistance for the heavy oil here was no longer due to the high viscosity but rather to the interfacial tension and conformance issues, in which case even further increased sodium mass would not contribute to more oil extraction. The overall incremental oil recovery factor $\mathrm{R}_{\mathrm{f}}$ by nanofluid was $38.5 \%$ of OOIP, in contrast to $6.5 \%$ of OOIP by using silicone oil alone, demonstrating that the sodium nanoparticles were much more effective in improving the overall oil recovery. Additionally, the $\mathrm{pH}$ of the water produced during the nanofluid experiment was measured and was found to be 12.5 , indicating that the in situ reaction of the sodium nanoparticles occurred within the porous cores.

\section{Oil sand (bitumen) recovery}

Batch tests

The static test samples detailed in Table 2 were prepared and observed for color change of the transparent liquid phase. As the photographs in Figure 3 (images labeled with o h) show, no combination of brine, silicone oil, or nanofluid could extract any oil from the oil sands without soaking time regardless of temperature. For the case of silicone-oil-based sodium nanofluid and brine, the color change of the liquid phase indicates that oil was liberated from the oil sands after soaking for $72 \mathrm{~h}$ at $22{ }^{\circ} \mathrm{C}$, and, based on visual observation, the mixture appears darker when soaked at $50{ }^{\circ} \mathrm{C}$ (see Figure $3 \mathrm{C}$ ). In contrast, neither silicone oil nor brine appeared to result in any color change, indicating that little to no oil was liberated even after $408 \mathrm{~h}$ of soaking at $50{ }^{\circ} \mathrm{C}$. These qualitative results indicate that the sodium nanoparticles react with brine to provide a mechanism for oil extraction from the oil sands and that the silicone oil serving as the dispersant does not aid in the process. 
Table 4. Heavy oil recovery factor by means of core flooding using either silicone oil or silicone-oil-based nanofluid at room temperature

\begin{tabular}{ll}
\hline Synthetic sandstone core experiment No. & $\mathbf{R}_{\mathbf{f}}(\%$ OOIP) \\
\hline 1 (silicone oil) & 6.5 \\
2 (nanofluid) & 38.5 \\
\hline
\end{tabular}

OOIP: Original oil in place.

While these observations are promising for this application, it would be premature to conclude that results similar to those of the Heavy Oil Core Flood experiments (above) would be obtained. With a relatively high viscosity, silicone oil could result in better mobility and help to distribute the nanoparticles but could also adhere to the oil sand surfaces, limiting exposure to the sodium nanoparticles. Thus, it was necessary to measure the oil recovery using silicone-oil-dispersed sodium nanoparticles in flow experiments.

\section{Packed oil sand flow experiments}

The porosity and permeability values of the three oil-sand cores are shown in Table 5, and all fall into the category of highly permeable and porous. Nearly no oil was detected in the effluent fluid following core flood No. 1 using silicone-oil-based nanofluid, contrary to expectations based on the batch experiments. Since it is evident from the batch tests that the sodium nanoparticles resulted in oil extraction from the oil sands, a logical conclusion is that the silicone oil dispersant prevented the reactions during the flow experiment. To explore this possibility further, an alternative dispersant, pentane, with a much lower viscosity than silicone oil, was tested in a flow experiment, as well as alone for a control experiment to quantify oil extraction attributed to the dispersant. In the control experiment, pentane alone resulted in a recovery of 14.9 wt.\% OOIP as shown in Table 6, while adding sodium nanoparticles to pentane significantly boosted the recovery to $33.6 \mathrm{wt}$ \% OOIP. Pentane has a low molecular weight and is soluble within the crude oil, allowing it to penetrate the oil sands matrix in order to lower the bitumen viscosity and contribute to the oil recovery factor.

The oil recovery mechanisms of sodium nanofluid in both applications studied here are complicated: depending on the use of pentane- or silicone-oil-dispersed sodium nanoparticles, multiple effects are introduced, including heat generation ${ }^{[31]}$, reactions between aromatic compounds in the oil and the sodium $^{[36]}$, pentane dissolution into oil ${ }^{[37]}$ that results in oil swelling ${ }^{[38]}$, the reaction of sodium hydroxide with naphthenic acids in the oil for in situ saponification ${ }^{[33]}$, surface wettability change induced by sodium hydroxide ${ }^{[39]}$, and possible in situ oil upgrading and phase miscibility enhancement by hydrogen gas ${ }^{[40,41]}$. Additional studies focusing on these mechanisms would be recommended to scale up the use of sodium nanoparticles in these two oil recovery applications.

To achieve actual practical applications, pilot tests should first be conducted. Inexpensive and scaled-up nanomaterial synthesis is the prerequisite for practical applications. As indicated by the synthetic method described here, large quantities of sodium nanoparticles should be easily obtained since the nanoparticles used here were synthesized in a few minutes by a top-down method using mechanical force. No chemical reaction occurs during the process, nor is any purification process needed. However, the engineering design of each treatment is required to achieve a maximum net profit. Lab flooding experiments should be conducted to obtain estimated values of material costs and profits from produced oil based on current oil prices. Evaluation of reservoir damage resulting from the use of sodium nanofluid may also be needed since the $\mathrm{pH}$ of the effluent water is high. In fact, re-injection of the water produced is highly recommended in this case since it can be used as alkaline flooding for conventional oil, minimizing the impact on surface environments. Additionally, we anticipate that the use of the sodium nanofluid may not be limited to heavy 
Table 5. Physical properties of packed oil sands used in flooding tests

\begin{tabular}{llllll}
\hline Packed oil sand core \# (test) & Oil sand mass $(\mathbf{g})$ & Length $\mathbf{( c m )}$ & Diameter $(\mathbf{c m})$ & Porosity (\%) & Permeability (D) \\
\hline 1 (SN) & 127 & 15.00 & 2.50 & 27.0 & 15.0 \\
2 (pentane) & 130 & 15.00 & 2.50 & 26.1 & 13.8 \\
3 (PN) & 129 & 15.00 & 2.50 & 26.9 & 14.5 \\
\hline
\end{tabular}

SN: Silicone-oil-dispersed sodium nanoparticles; PN: pentane-dispersed sodium nanoparticles.

Table 6. Oil sand recovery performance at room temperature

\begin{tabular}{lll}
\hline Packed oil sand core \# (test) & Original oil mass $(\mathbf{g})$ & $\mathbf{R}_{\mathbf{f}}(\%$ OOIP) \\
\hline 1 (SN) & 16.1 & 0 \\
2 (pentane) & 16.5 & 14.9 \\
3 (PN) & 16.4 & 33.6 \\
\hline
\end{tabular}

SN: Silicone-oil-dispersed sodium nanoparticles; PN: pentane-dispersed sodium nanoparticles; OOIP: original oil in place.

oil recovery since the reaction between sodium and water also shows multiple benefits for conventional oil recovery, the removal of water blockages in gas reservoirs, wettability alteration, oil pipeline transport, etc. Hydrogen gas generated by the reaction could provide energy within the reservoir and, if the local pressure surpasses the fracture initiation pressure as gas is generated in the confined pores, the permeability of the rock could be enhanced, which is beneficial for fluid flow ${ }^{[42]}$. Clearly, the sodium nanofluid may also be used to replace the fracturing fluid in fracking to extract oil and natural gas.

\section{CONCLUSIONS}

Results from flow experiments demonstrated the potential of using sodium nanofluid for recovery of both heavy oil with a viscosity of $2000 \mathrm{cP}$ and extremely viscous oil within oil sands. Control experiments for each application provided evidence that the sodium nanoparticles played a highly significant role in oil recovery. It was found that sodium nanofluid has great potential to mobilize residual heavy oil inside the porous media by generating heat, hydrogen gas, and alkali. For oil sands, proper dispersant selection and post-injection soaking are both important for extracting a high percentage of oil since it binds strongly to the mineral surfaces, increasing the difficulty of mobilization in comparison with the case of $2000-\mathrm{cP}$ oil.

\section{DECLARATIONS}

\section{Author' contributions}

Guided the designing and experimental work: Ren Z, Kostarelos K

Analyzed the data and results: Zareei D, Luo D, Kostarelos K, Ren Z

Reviewed and revised the manuscript: Zareei D, Luo D, Kostarelos K, Ren Z

Supervised the laboratory work: Ren Z, Kostarelos K

\section{Availability of data and materials}

Not applicable.

\section{Financial support and sponsorship}

None

\section{Conflicts of interest}

All authors declared that there are no conflicts of interest. 


\section{Ethical approval and consent to participate}

Not applicable.

\section{Consent for publication}

Not applicable.

\section{Copyright}

(c) The Author(s) 2021.

\section{REFERENCES}

1. Lee J, Babadagli T. Comprehensive review on heavy-oil emulsions: colloid science and practical applications. Chem Eng Sci 2020;228:115962. DOI

2. Guo K, Li H, Yu Z. In-situ heavy and extra-heavy oil recovery: a review. Fuel 2016;185:886-902. DOI

3. Czarnecki J, Radoev B, Schramm LL, Slavchev R. On the nature of Athabasca oil sands. Adv Colloid Interface Sci 2005;114-115:5360. DOI PubMed

4. Chopra S, Lines L, Schmitt DR, Batzle M. 1. Heavy-oil reservoirs: their characterization and production. In: Chopra S, Lines LR, Schmitt DR, Batzle ML, editors. Heavy oils. Society of Exploration Geophysicists; 2010. p. 1-69.

5. Lin F, Xu Y. Impact of a novel bitumen extraction process on mined oil sands tailings behavior. AIChE J 2019;65:250-8. DOI

6. Zhou JZ. Role of mineral flotation technology in improving bitumen extraction from mined A thabasca oil sands III. Next generation of water-based oil sands extraction. Can J Chem Eng 2021;99:755-77. DOI

7. Shah A, Fishwick R, Wood J, Leeke G, Rigby S, Greaves M. A review of novel techniques for heavy oil and bitumen extraction and upgrading. Energy Environ Sci 2010;3:700. DOI

8. Leyva-gomez H, Babadagli T. Efficiency of heavy-oil/bitumen recovery from fractured carbonates by hot-solvent injection. $J$ Pet Sci Eng 2018;165:752-64. DOI

9. Dong X, Liu H, Chen Z, Wu K, Lu N, Zhang Q. Enhanced oil recovery techniques for heavy oil and oilsands reservoirs after steam injection. Appl Energy 2019;239:1190-211. DOI

10. Huang K, Zhu W, Sun L, Wang Q, Liu Q. Experimental study on gas EOR for heavy oil in glutenite reservoirs after water flooding. $J$ Pet Sci Eng 2019;181:106130. DOI

11. Yang Y, Li L, Wang X, et al. A surfactant for enhanced heavy oil recovery in carbonate reservoirs in high-salinity and hightemperature conditions. Energies 2020;13:4525. DOI

12. Sedaghat MH, Ghazanfari MH, Masihi M, Rashtchian D. Experimental and numerical investigation of polymer flooding in fractured heavy oil five-spot systems. J Pet Sci Eng 2013;108:370-82. DOI

13. Jamaloei B, Dong M, Mahinpey N. Experimental and numerical study of strategies for improvement of cyclic solvent injection in thin heavy-oil reservoirs. SPE Reserv Evaluation Eng 2020;24:127-58. DOI

14. Gao C, Li X, Guo L, Zhao F. Heavy oil production by carbon dioxide injection. Greenhouse Gas Sci Technol 2013;3:185-95. DOI

15. Zhou X, Yuan Q, Peng X, Zeng F, Zhang L. A critical review of the $\mathrm{CO}_{2}$ huff ' $\mathrm{n}$ ' puff process for enhanced heavy oil recovery. Fuel 2018;215:813-24. DOI

16. Davarpanah A, Mirshekari B. Experimental study of $\mathrm{CO}_{2}$ solubility on the oil recovery enhancement of heavy oil reservoirs. $J$ Therm Anal Calorim 2020;139:1161-9. DOI

17. Dai C, Wang X, Li Y, et al. Spontaneous imbibition investigation of self-dispersing silica nanofluids for enhanced oil recovery in lowpermeability cores. Energy Fuels 2017;31:2663-8. DOI

18. Luo D, Zhang F, Ding F, Ren B, Ren Z. Interactions between amphiphilic Janus nanosheets and a nonionic polymer in aqueous and biphasic systems. Soft Matter 2019;15:7472-8. DOI PubMed

19. Tarboush BJ, Husein MM. Adsorption of asphaltenes from heavy oil onto in situ prepared NiO nanoparticles. J Colloid Interface Sci 2012;378:64-9. DOI PubMed

20. Mazloom M, Hemmati-sarapardeh A, Husein MM, Shokrollahzadeh Behbahani H, Zendehboudi S. Application of nanoparticles for asphaltenes adsorption and oxidation: a critical review of challenges and recent progress. Fuel 2020;279:117763. DOI

21. Taborda EA, Franco CA, Lopera SH, Alvarado V, Cortés FB. Effect of nanoparticles/nanofluids on the rheology of heavy crude oil and its mobility on porous media at reservoir conditions. Fuel 2016;184:222-32. DOI

22. Taborda EA, Franco CA, Ruiz MA, Alvarado V, Cortés FB. Experimental and theoretical study of viscosity reduction in heavy crude oils by addition of nanoparticles. Energy Fuels 2017;31:1329-38. DOI

23. Saha R, Uppaluri RVS, Tiwari P. Silica nanoparticle assisted polymer flooding of heavy crude oil: emulsification, rheology, and wettability alteration characteristics. Ind Eng Chem Res 2018;57:6364-76. DOI

24. Wang J, Liu L, Zhang L, Li Z. Aquathermolysis of heavy crude oil with amphiphilic nickel and iron catalysts. Energy Fuels 2014;28:7440-7. DOI

25. Lakhova A, Petrov S, Ibragimova D, et al. Aquathermolysis of heavy oil using nano oxides of metals. J Pet Sci Eng 2017;153:385-90. DOI

26. Yi S, Babadagli T, Andy Li H. Use of nickel nanoparticles for promoting aquathermolysis reaction during cyclic steam stimulation. SPE Journal 2017;23:145-56. DOI 
27. Luo D, Wang F, Zhu J, et al. Nanofluid of graphene-based amphiphilic Janus nanosheets for tertiary or enhanced oil recovery: High performance at low concentration. Proc Natl Acad Sci U S A 2016;113:7711-6. DOI PubMed PMC

28. Luo D, Wang F, Zhu J, et al. Secondary oil recovery using graphene-based amphiphilic Janus nanosheet fluid at an ultralow concentration. Ind Eng Chem Res 2017;56:11125-32. DOI

29. Pei H, Shu Z, Zhang G, et al. Experimental study of nanoparticle and surfactant stabilized emulsion flooding to enhance heavy oil recovery. J Pet Sci Eng 2018;163:476-83. DOI

30. Lee J, Huang J, Babadagli T. Dynamics of emulsion generation and stability during heavy oil displacement with chemicals and nanoparticles: qualitative analysis using visual 2D data. Fuel 2020;270:117502. DOI

31. Luo D, Ren Z. Synthesis of sodium nanoparticles for promising extraction of heavy oil. Mater Today Phys 2021;16:100276. DOI

32. Mason PE, Uhlig F, Vaněk V, Buttersack T, Bauerecker S, Jungwirth P. Coulomb explosion during the early stages of the reaction of alkali metals with water. Nat Chem 2015;7:250-4. DOI PubMed

33. Saha R, Uppaluri RV, Tiwari P. Influence of emulsification, interfacial tension, wettability alteration and saponification on residual oil recovery by alkali flooding. J Ind Eng Chem 2018;59:286-96. DOI

34. Comer $\mathrm{T}$. The effect of iron bearing minerals on surfactant adsorption in chemical enhanced oil recovery applications. Available from: https://hdl.handle.net/10657/4527. [Last accessed on 15 Sep 2021].

35. Sharma P, Kostarelos K, Xiong X. Single phase microemulsions applied to oil sands. SPE Western Regional Meeting; 2018. DOI

36. Styles Y, de Klerk A. Sodium conversion of oilsands bitumen-derived asphaltenes. Energy Fuels 2016;30:5214-22. DOI

37. Nourozieh H, Kariznovi M, Abedi J. Viscosity measurement and modeling for mixtures of Athabasca bitumen/n-pentane at temperatures up to $200^{\circ} \mathrm{C}$. SPE Journal 2014;20:226-38. DOI

38. Bayat M, Lashkarbolooki M, Hezave AZ, Ayatollahi S. Investigation of gas injection flooding performance as enhanced oil recovery method. J Nat Gas Sci Eng 2016;29:37-45. DOI

39. Gong H, Li Y, Dong M, Ma S, Liu W. Effect of wettability alteration on enhanced heavy oil recovery by alkaline flooding. Colloids Surf A Physicochem Eng Asp 2016;488:28-35. DOI

40. Hart A, Leeke G, Greaves M, Wood J. Down-hole heavy crude oil upgrading by CAPRI: effect of hydrogen and methane gases upon upgrading and coke formation. Fuel 2014;119:226-35. DOI

41. Omar AE. Some aspects of miscible flooding with refinery flare gas. Energy Sources 1991;13:217-28. DOI

42. Li Z, Xu H, Zhang C. Liquid nitrogen gasification fracturing technology for shale gas development. J Pet Sci Eng 2016;138:253-6. DOI 